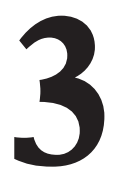

\title{
EL «DE MODO ADDISCENDI» (C.1263) DE GILBERT DE TOURNAI O.F.M., UN PUENTE ENTRE LA TRADICIÓN Y EL RENACIMIENTO
}

(THE «DE MODO ADDISCENDI» (C. 1263) OF GILBERT DE TOURNAI O.F.M., A BRIDGE BETWEEN TRADITION AND THE RENAISSANCE)

Javier Vergara

UNED

DOI: $10.5944 / e d u c x x 1.2 .16 .10332$

Cómo referenciar este artículo/How to reference this article:

Vergara, J. (2013). El «De modo addiscendi» (c.1263) de Gilbert de Tournai O.F.M., un puente entre la tradición y el Renacimiento. Educación XX1, 16 (2), 63-82. doi: 10.5944/educxx1.2.16.10332 Vergara, J. (2013). The «De modo addiscendi» (c. 1263) of Gilbert de Tournai O.F.M., a bridge between tradition and the Renaissance. Educación XX1, 16 (2), 63-82. doi: 10.5944/educxx1.2.16.10332

\section{RESUMEN}

El renacimiento cultural que se produce en los siglos XII y XIII dio origen a una producción literaria abundante que tuvo en la educación uno de sus ejes más significativos. Un ejemplo patente es el De modo addiscendi, obra publicada hacia 1263, por el franciscano Gilbert de Tournai, en la que se resume una buena parte de la pedagogía escolástica. La obra, no traducida a lengua viva y apenas estudiada por la historiografía pedagógica, tiene por objeto mostrar cómo el maestro y el discípulo debían alcanzar la sabiduría. Un intento loable cuyo estudio y conocimiento ha exigido traducir y comparar diferentes manuscritos latinos, a la vez que analizar los principales estudios realizados sobre el tema. El resultado confirma a Gilbert de Tournai como uno de los pedagogos más importantes del siglo XIII y un puente de unión entre la tradición y la educación renacentista, que la historiografía pedagógica debe reivindicar y actualizar, siendo este trabajo una mínima aportación a su causa.

\section{ABSTRACT}

The cultural revival occurred between the twelfth and thirteenth centuries produced a large and diverse literary production. The abundant literature on education is a significant example. A clear and visible example is the De modo addiscendi. This work was published around 1263, by the Franciscan monk Gilbert of Tournai. This book is a summary and a very accomplished 
synthesis of scholastic education. The work has not been translated into any modern language, is almost unknown by historians of education. This publication tries to show how the teacher and the student must achieve wisdom. The knowledge of this process has required two important conditions: first, to translate and compare different Latin manuscripts, and second, to analyze the major studies on the subject. The result endorses that Gilbert of Tournai is a very important educator of the thirteenth century and a bridge between tradition and Renaissance education. This is an important conclusion that historiography must accept and update, and in respect to which this article is only a minimal contribution.

\section{VIDA Y OBRA}

Muy poco es lo que sabemos de la vida de Gilbert de Tournai. Los datos que la historiografía nos ha deparado sobre este filósofo, teólogo y pedagogo son escasos y algunos de ellos inciertos y dudosos. Sí se sabe que nació en los primeros años del siglo XIII en la diócesis de Tournai (actual Bélgica). Algunos historiadores señalan como fecha más probable de su nacimiento 1209 (Bonifacio, 1953, 9). Profesó en la orden franciscana hacia 1235, fue estudiante y más tarde maestro de Teología en la Universidad de París, cargo que seguramente desempeñó en dos etapas: una primera antes de 1245 y una segunda entre 1257 y 1260, sucediendo en la cátedra a Buenaventura de Bagnoriejo (Glorieux, 1933, 311). Una responsabilidad que, como él mismo nos dice, abandonó por un golpe de gracia de Dios para dedicarse al cultivo del hombre interior (De modo addiscendi, 1263, Pars I, c. I, 60).

Gilberto fue un predicador fecundo y hombre cercano a la corte de Luis IX de Francia, para quien escribió Eruditio regum et principum, con el propósito de que sirviera de crecimiento espiritual al monarca, a sus criados y a sus hijos. Fue también confesor de la princesa Isabel (1225-1270), abadesa de Longchamp y hermana de Luis IX, a ella dedicó en 1270 su De virginitate. Algunos eruditos han afirmado que participó con el propio San Luis en la cruzada de 1248-1254, que fue un consejero cercano e incluso lector de la familia real (Glorieux, 1933, n 311, 56). Extremos que están por probar y a los que él nunca aludió en sus escritos. Nuestro franciscano murió el 4 de octubre de 1284, tras una vida fecunda como maestro y hombre de letras (Troeyer, 1974, 17).

Su producción escrita fue una vasta obra, de varios bloques temáticos, algunos de cuyos títulos son de dudosa autenticidad. Entre sus obras pedagógicas destacan: Rudimentum doctrinae (c.1259-1270), De modo addiscendi (c.1264/65) y Eruditio Regum et Principum. (1259); entre sus escritos hagiográficos sobresalen: Vita Sancti Eleutherii. (c.1263) y Pharetra. (c.1260); escribió también obras ascéticas: Tractatus de pace et tranquilitate animi. 
(c.1276), apologéticas: Collectio de scandalis Ecclesiae (1273), y homilías varias: Sermones dominicales et de Sanctis (c.1255) (Bonifacio, 1953, 14-20).

\section{TRATADO DE UNA OBRA MÁS AMPLIA}

Cuando el lector avezado en la pedagogía bajomedieval aborda por primera vez la lectura del De modo addiscendi puede tener la impresión de estar ante una obra incompleta de la pedagogía escolástica. Su temática, centrada exclusivamente en mostrar cómo el maestro y el discípulo alcanzan la sabiduría, deja de lado cuestiones clave de la estructura noética de la educación: fines, agentes, medios, etc. Esta duda inicial se despeja con prontitud si nos adentrarnos en la totalidad de la obra pedagógica de Gilbert de Tournai. Es entonces cuando se comprueba que el De modo addiscendi no es una obra autónoma e independiente de nuestro franciscano, sino la tercera parte de una enciclopedia pedagógica suya, que tituló Rudimentum doctrinae christianae, en la que trataba las cuatro causas de la educación: final, eficiente, formal y material, y, que, salvo el De modo, permanece todavía inédita.

Una fragmentación que no resultaba inusual en el marco enciclopédico de la cultura escolástica. En esa época, la amplitud de las obras obligaba a los autores a publicar sus trabajos de forma escalonada en opúsculos o tratados separados. Circunstancia que se veía agrandada por las copias posteriores que no necesariamente trascribían la totalidad de la obra sino una parte de la misma. Tal es el caso del De modo addiscendi, que nos ha llegado como un tratado independiente cuando en realidad es la causa formal o tercer tratado de una magna enciclopedia pedagógica denominada Rudimentum doctrinae, y publicada entre 1259 y 1269 (Gieben, 1963, 147).

Esta obra supone unos de los intentos más ambiciosos de la cultura escolástica por abordar un análisis completo sobre la estructura noética de la educación. Una empresa que Tournai dividió en cuatro tratados o causas pedagógicas. Al primero le asignó la causa final. Un tratado de tres capítulos en los que describía el fin principal por el cual se ha creado el alma racional (propter sapientiam obtinendam), y el fin último al cual se ordena la sabiduría misma (la vida eterna). En su primer capítulo analizaba cómo el conocimiento y posesión de la verdad es fin primario y último de la naturaleza, haciendo especial hincapié en los errores que al respecto han manifestado los sabios de la historia. En el segundo, trataba un tema recurrente: las muchas posibilidades que ofrecen los saberes y cómo todos deben conducir a la suprema Teología. Cierra el tratado un tercer capítulo, igualmente recurrente: el hombre como criatura de Dios, caído y redimido, con un fin claro y definido: la vida eterna o reencuentro con el creador. (Gieben, 1963, 153). 
El segundo tratado es un análisis sobre la causa eficiente de la educación. A lo largo de siete capítulos, Tournai analiza gradualmente los agentes de la sabiduría. Como buen franciscano, que rezuma un fuerte agustinismo aristotélico, nos dice con vehemencia que el principal agente de la educación es Dios mismo y por participación le siguen: los ángeles, Jesucristo, los hombres elegidos y en quienes Él ha delegado: los apóstoles, los sumos pontífices, los obispos y los predicadores. El resultado será un maestro clericalizado, identificado con la figura de Cristo, y con la misión irreductible de conducir almas a Dios, por la fuerza de la doctrina, la moral y la gracia (Gieben et Bérubé, 1973, 598).

El tercer tratado es el De modo addiscendi. Se refiere a la causa formal de la educación. En sus seis partes y 68 capítulos Tournai aborda la adquisición misma de la sabiduría en relación al maestro y al discípulo. De todas sus partes, la más importante y novedosa es sin duda la cuarta, referida a las exigencias del entendimiento. Un tema que supera a la tradición brindando uno de los mejores estudios escolásticos sobre el uso de la memoria y sus posibilidades (Maranesi, 1988, II, 665).

Cierra el Rudimentum doctrinae un cuarto tratado dedicado a la causa material de la educación y más en concreto a las ciencias que actualizan la sabiduría. Representa la visión que Tournai tiene del conocimiento y de sus partes. En primer lugar sitúa el quadrivium de la elocuencia, conformado por: gramática, poética, lógica y retórica; a continuación le sigue el quadrivium intelectivo, compuesto por: aritmética, música, geometría y astronomía; en tercer lugar aparece el quadrivium activo: física, ética, mágica y metafísica; y, por último, el quadrivium afectivo, conformado por: hagiografía, profética, evangélica y apostólica. Desgraciadamente este cuarto tratado, que Tournai consideraba «el más difícil y sutil», está perdido y sólo se conserva de él un resumen en el llamado códice de Florencia (Maranesi, 1988, II, 675).

\section{ORIGEN, ESTRUCTURA Y CONTENIDO}

¿Cómo surge el De modo addiscendi? En concreto es una petición expresa de Michele de Lille, antiguo compañero de Gilbert de Tournai en la Universidad de París y en su día rector de la misma, para que nuestro franciscano le escriba un tratado que pueda servirle de ayuda para guiar la educación de su preceptuado, a la sazón Jean Dampierre, preboste de San Donatiano en Brujas — de unos 18 años de edad- e hijo del conde de Flandes. Tournai le responde afirmativamente, pues dispone de tiempo por estar ya liberado de las obligaciones universitarias y consagrado al cultivo del hombre interior (De modo addiscendi, 1263, Pars I, c. I, 61-62). 
El resultado será uno de los intentos más acabados de la pedagogía escolástica por mostrar cómo el maestro y el discípulo debían alcanzar la sabiduría. Propósito que Tournai estructuró en seis partes y 68 capítulos, que, a tenor de su contenido, conformaban lo que la escolástica aristotélica denominó la causa formal de la educación. Su distribución temática fue la siguiente:

$1^{\text {a: }}$ Importancia del aprendizaje y del estudio, 8 capítulos

$2^{\text {a }}$ : Sobre el papel del profesor, 13 capítulos

$3^{\text {a: }}$ Sobre la instrucción del alumno, 10 capítulos

$4^{\mathrm{a}}$ : Cómo es la enseñanza, 27 capítulos

5: Progreso y perfeccionamiento en el estudio, 4 capítulos

$6^{\text {a: }}$ Progreso de los perfectos, 6 capítulos

La primera parte, que tiene un carácter introductorio, supone de manera irreversible la apuesta clara de la escolástica por una cultura pedagógica e intelectual abiertamente clásica, paleocristiana y secular. Tournai verá en el estudio - siguiendo el Didascalicon de Hugo de San Víctor-, las cuatro recompensas clave de la dignidad humana: reconocimiento de la verdad, adquisición de la santidad, muestras de consideración y posesión de la felicidad. Recompensas que competían a todo hombre, pero especialmente a los nobles. A ellos se demandaba más que a nadie ser modelos de ejemplaridad y santidad; modelos llamados a arrastrar, a buscar el bien común y sobre todo a colaborar con la Iglesia en la salvación de todos y cada uno de los súbditos. Exigencias que demandaban en el noble tres condiciones inexcusables: primero, ignorar la pasión de la cetrería, por ahuyentar como nadie el espíritu del alma; segundo, comenzar en casa y con el inicio de la adolescencia la educación formal o cultivo de la inteligencia; finalmente, rechazar las malas compañías y pasiones de la amistad, las primeras desviaban de la ciencia, las segundas precipitaban a los vicios (De modo addiscendi, 1263, Pars I, 59-79).

La segunda parte se centró en el elemento capital de la pedagogía escolástica: el maestro. Una figura que Tournai inspirará en el De magistro agustiniano y en la Metafísica aristotélica. Para nuestro franciscano, el maestro debía ser un Cristo redivivo, capaz de llevar al discípulo de los principios a las conclusiones, de la potencia al acto. Una responsabilidad clave que le llevó a enfatizar en extremo tres aspectos de la actividad magisterial: las cualidades del maestro, cómo personalizar la educación y cómo corregir. Sobre las cualidades docentes, dirá que el magisterio debe apoyarse en la excelencia de cuatro pilares: moralidad intachable, ciencia sólida, facilidad de palabra y habilidad pedagógica. A continuación, con la ayuda de Vicente de Beauvais, se detuvo en cómo personalizar la educación, exigencia que demandaba tres requisitos: contemplar la edad del discípulo, un método 
adecuado y la adecuación de los contenidos a las realidades personales. Finalmente, con el apoyo de Séneca, teorizó sobre la pertinencia de la corrección, que debía ser exhortatoria, conminatoria, reprochadora y frecuente, incluyendo el uso de varas, palmetas, azotes y látigos, para así iluminar el camino, desarraigar los vicios y cauterizar las heridas (De modo addiscendi, 1263, Pars II, 81-104).

La tercera parte del De modo addiscendi se centró en la figura del discípulo. Otro de los elementos clave de la pedagogía escolástica que Tournai sistematizó con textos de Séneca, Cicerón, Ovidio, San Agustín y el PseudoBoecio. Referentes recurrentes que no impidieron las ideas propias de nuestro franciscano. Para Tournai, el discípulo no es sólo el intelectual estoico que ha doblegado las pasiones, afirmado el espíritu y cultivado la verdad intelectual. Es sobre todo el hombre interior que con un proceso secuencial de humildad y oración llega a la contemplación divina por la fuerza de la santidad. Esta es una de las mayores aportaciones de nuestro franciscano. Un perfil que habría de marcar la pedagogía de su Orden. Un proceso que en buena parte de dirimía en un decálogo de virtudes insoslayables. La primera debía ser la sumisión voluntaria al maestro, condición necesaria e indispensable para erradicar la soberbia; a continuación venía la discreción, que aseguraba la moderación y control de las pasiones, templando el alma para mayores empresas; en tercer lugar estaba la paciencia o tolerancia, considerada la base y antesala de todo triunfo; en cuarto lugar venía la obediencia, consistente en convertir en propia la voluntad del que ordena; en quinto, el recogimiento y concentración, que demandaba desocuparse de las cosas superfluas y centrarse en lo importante; en sexto, escuchar al maestro directamente, sin desagrado o vacilación alguna; en séptimo, aplicar la razón interior, apartándose de los sentidos de la carne, para discernir y abstraer lo oculto de las cosas; en octavo, practicar la docilidad o deseo constante de llegar a la excelencia o dominio en la praxis; en noveno, practicar la humildad; y en décimo, apoyarse en la fuerza de la religión huyendo de todo narcisismo o autosuficiencia. El resultado será el ideal de un alumno típicamente franciscano, que habría de llenar buena parte de los principales idearios pedagógicos hasta bien entrado el Renacimiento (De modo addiscendi, 1263, Pars III, 105-130).

La cuarta parte del De modo addiscendi es sencillamente otra cosa. Si hasta ahora las obras de pedagogía habían sido fundamentalmente tratados didácticos, esta parte, de 27 capítulos, la más larga de todas, será todo un tratado de psicología cognitiva franciscana sobre cómo pensamos Un intento llamado a desgranar la naturaleza de los cuatro elementos determinantes del pensamiento: los sentidos, la inteligencia, la memoria y la razón. Análisis que no estará exento de los conocimientos biológicos de la época, gracias sobre 
todo al conocimiento de la ciencia árabe, y que convertirá a Tournai en uno de los referentes obligados de la psicología cognitiva medieval.

En sus primeros cinco capítulos, nuestro franciscano nos habla de los sentidos como la primera puerta del pensamiento. Una vía sensitiva que da lugar a cinco grados de conocimiento: la impresión, llamada a percibir las forma de lo corpóreo; la imaginación, que capta las cualidades de esas formas; la razón, que extrae sus esencias; la inteligencia, que extrae lo incorpóreo de las formas no sensibles; y, finalmente, la comprensión que es un dialogo o contemplación de Dios sin mediaciones.

A continuación Tournai se recrea en el entendimiento. En nueve capítulos, de rancio sabor agustiniano - del sexto al decimocuarto-, nos dice con laconismo y vehemencia cómo actualizar la inteligencia. Una facultad infundida por Dios — la que más nos asemeja a él— que tiene por misión buscar la sabiduría; es propia de los hombres, se ayuda con la práctica, se agudiza con el ejercicio moderado y se embota con el trabajo excesivo. Todo un tratado didáctico que huye de la teoría para asentarse en una praxis que debe llevar al hombre al dominio y trascendencia de la realidad.

Le sigue en el análisis la naturaleza de la memoria. En cuatro capítulos muy ciceronianos - del quince a dieciocho- nos dice que es una potencia del alma llamada a actualizar lo que ha existido, pudiendo ser de dos tipos: sensible o inteligible. La primera, que se sitúa en la parte anterior del cerebro, almacena las impresiones corpóreas o meramente sensitivas, siendo propia de los niños, de los animales y de las personas de complexión húmeda, pues su temperamento no le permite ir más allá de lo sensible. La segunda, situada en la parte posterior del cerebro, almacena las ideas o conceptos que trascienden a las formas sensibles, es propia de los ángeles, de los hombres formados y de aquellos que tienen una complexión cálida, también se denomina o recuerdo activo.

Tournai cierra su teoría cognitiva abordando, en los capítulos 19 a 27, la naturaleza de la razón. Una facultad clave a la que compete discernir y juzgar, mediante el ejercicio y la experiencia, lo que la memoria guarda, retiene o recuerda. Una tarea nada fácil que, entre otras cosas, exige un plan pedagógico con cuatro condiciones indispensables: humildad de entendimiento para llevar las sensaciones y conceptos al juicio de las verdades eternas; aplicación rigurosa de una pedagogía vigilante basada en el esfuerzo, en el amor o studiositas, en la atención y en la vigilancia; una normalidad emocional que favorezca una vida y actitudes santas; $y$, finalmente, una pobreza clara y patente que permita despegarse de los bienes o pasiones del mundo (De modo addiscendi, 1263, Pars IV, 131-248). 
Estas ideas podrían ser el corolario de las tesis tournacenses y poner fin a una obra justificada sobremanera por esta parte cuarta. Tournai sin embargo prefiere alargarla con dos partes redundantes, de hondo sabor didáctico. Una quinta parte, de cuatro capítulos, dedicada a cómo progresar en la enseñanza, y centrada casi por entero en las Collationes patrum de Casiano. Se trata de una obra del siglo IV, sustanciada en cuatro condiciones pedagógicas que según Tournai constituían la clave de la educación perfecta: aplacar las pasiones de la carne y del mundo, dirigir los estudios a temas divinos, graduar el conocimiento con orden y continuidad y considerar la gracia el motor que falta a la voluntad para alcanzar la intimidad Dios (De modo addiscendi, 1263, Pars V, 249-263).

El De modo addiscendi se cierra con una sexta parte dedicada al progreso de los perfectos. Atributo que Tournai asignó exclusivamente a las personas dedicadas a la vida religiosa. Es una parte corta, de seis capítulos, típicamente franciscana, en la que nuestro autor, con textos del Beniamin maior de Ricardo de San Víctor, se definirá como un consumado maestro de la vida interior. Para Tournai la sabiduría no está en la ciencia, no está en el conocimiento, está en la contemplación. Una especie de estado o fase secuencial progresiva que no se da ni puede darse en la acción secular sino en el hombre interior por medio de la meditación, la oración y la santidad (De modo addiscendi, 1263, Pars VI, 265-290).

\section{ESTILO}

Lo primero que llama la atención a la hora de leer el De modo addiscendi es su estilo sistemático y claro. Lo que es muy de agradecer en la no siempre nítida retórica pedagógica del siglo XIII. Estamos ante un autor ordenado, de frases cortas, con juicios vehementes y aficionado al auxilio de textos no siempre exactos y literales, que en ocasiones son forzados, cuando no cambiados, para servir al orden, claridad y propósitos del autor. Una apuesta que Gilbert de Tournai cifró en la virtualidad didáctica de tres parámetros metodológicos que marcaron la identidad de su obra: la importancia de las sentencias, el uso reiterado y preciso de la quaestio y la recurrencia sistemática a lo que él llamó variables cuaternarias.

Sobre el uso de escribir y argumentar sobre sentencias cabe decir que no estamos ante una práctica exclusiva de Tournai, sino ante un método antiguo y muy arraigado de la cultura medieval. Las gentes del saber del bajo medievo pensaban que la historia tenía un eminente valor didáctico y que en las res gestae o sucesos históricos podían aprenderse registros o pautas que contribuyeran a la mejora del hombre. Sólo había que almacenarlos, guardarlos y mostrarlos como ejemplos de autoridad y sabiduría. Una praxis 
que la escolástica medieval desarrolló en extremo, elaborando colecciones o flores de la historia que sirvieron de fuentes documentales para ilustrar la doctrina, para animar los sermones o para ayudar a la enseñanza (Vergara, 2003, 511-526).

Nuestro franciscano fue un consumado experto en usar esos recursos. Técnica que en modo alguno restó mérito y originalidad a su obra. Él fue el responsable de la recopilación, selección, organización e interpretación de los textos de su trabajo. En dinámicas de esta naturaleza es muy importante distinguir entre originalidad literaria y originalidad conceptual. Y en el De modo addiscendi no habla Agustín, Jerónimo, Hugo de San Víctor o el Pseudo-Boecio sino Gilbert de Tournai con palabras de Agustín u otros maestros de la historia. El resultado fue un edificio de estilo tournacense, con bastante orden y concierto, que convirtió a nuestro protagonista en uno de los autores más sistemáticos de la pedagogía medieval.

El por qué de ello hay que buscarlo en el uso brillante, preciso y eficaz que hizo de la quaestio. Si hasta el siglo XII las gentes del saber aprendieron, reflexionaron y escribieron con el sistema didáctico de la lectio, es decir reproduciendo con reiteración las sentencias del pasado, las gentes del siglo XIII darán un paso adelante. Buscarán una nueva sensibilidad caracterizada por someter los textos a crítica, a duda y a la conclusión o juicio del maestro. Una novedad importante que disminuyó el número de sentencias en las obras y elevó al docente a un principio de autoridad desconocido hasta entonces (Vergara, 2007, 519-545). El resultado fue la aparición de escuelas y de obras menos recurrentes, más reflexivas y sobre todo más originales. El De modo addiscendi es un claro exponente. No estamos ante una simple amalgama o yuxtaposición de textos. Estamos ante una estructura fija que comienza con el planteamiento de un problema, sigue con su delimitación o acotación por medio de sentencias de probada autoridad, y concluye con una crítica de las mismas o juicio magisterial que aspira a representar un avance del conocimiento.

Una dinámica, en ocasiones lenta pero válida, que nuestro franciscano cifró sobremanera en la virtualidad discursiva del número cuatro. Un intento por acotar en cuatro variables el contenido de los diferentes capítulos del De modo addiscendi. El porqué de ello no lo explicó. La escolástica fue muy dada a lo cabalístico y desde Pitágoras la tétrada se consideraba el número perfecto. Cuatro fueron los elementos constitutivos de la naturaleza, cuatro los evangelios, cuatro los puntos cardinales, cuatro los temperamentos psicológicos y cuatro los valores que Tournai eligió para explicar y acotar el contenido de su obra. Frases como: «De la cuádruple elocuencia del maestro», «De la cuádruple habilidad del maestro para enseñar», «Los cuatro aspectos de la instrucción», "Consideración de la inteligencia según 
cuatro aspectos»,... fueron sólo algunos títulos de los muchos capítulos que tuvieron al valor cuaternario como base estructural de su obra.

\section{FUENTES}

$\mathrm{Al}$ abordar el análisis de las fuentes del De modo addiscendi lo primero que llama la atención es el número tan importante y desigual de sus citas. Indudablemente no todas presentan el mismo valor o tienen igual entidad. Muchas son retóricas, otras están orientadas a embellecer el texto y otras marcan las ideas base de muchos capítulos. Entrando en su número, Gilberto manejó 816 sentencias: 224 pertenecen a la Sagrada Escritura y 592 a 88 autores diferentes. Las citas, extraídas en su mayoría de florilegios, colecciones y obras originales, las hemos agrupado en nueve bloques que arrojan el siguiente cómputo aritmético y porcentual:

\begin{tabular}{|c|l|r|r|}
\hline $\mathrm{N}^{\text {o de autores. }}$ & \multicolumn{1}{|c|}{ Tipo de citas } & Frecuencias & Porcentaje \\
\hline 25 & Veterotestamentarias & 167 & $20,46 \%$ \\
\hline 18 & Novotestamentarias & 57 & $6,98 \%$ \\
\hline 37 & Autores antiguos & 206 & $25,24 \%$ \\
\hline 17 & Padres latinos & 207 & $25,36 \%$ \\
\hline 7 & Padres griegos & 19 & $2,32 \%$ \\
\hline 13 & Pedagogía medieval & 130 & $15,93 \%$ \\
\hline 9 & Miscelánea medieval & 9 & $1,10 \%$ \\
\hline 1 & Autores cristiano-latinos & 8 & $0,98 \%$ \\
\hline 4 & Autores árabes & 13 & $1,59 \%$ \\
\hline
\end{tabular}

\subsection{Fuentes bíblicas}

Como se observa, las fuentes bíblicas, con 224 referencias, constituyen la autoridad más citada. Los escolásticos tenían un sentido jerarquizado de la verdad documental y las Sagradas Escrituras representaban la certeza por antonomasia, un camino sin posibilidad de error o desvío que debía marcar el destino y sentido del hombre.

Con esta firme convicción, Tournai se fijó especialmente en el Antiguo Testamento. Para la pedagogía escolástica este periodo tenía un sentido eminentemente educativo, representaba el arquetipo didáctico de un largo proceso que culminaba con la llegada de Cristo. Un tiempo de preparación en el que Dios había grabado los registros claves de la vida y de la dignidad 
humana. El reto era enhebrarlos, encontrar su sentido y asentar en sus referencias los sillares de la formación.

En primer lugar centró su atención en la virtualidad didáctica de los libros sapienciales. Un corpus que no trata tanto de sentimientos de culpa o expiación como enseñar al hombre el bien vivir, a comportarse en todas las circunstancias de la vida y a obtener la felicidad en esta tierra. De ellos extrajo 72 citas repartidas de forma desigual. Destacan 26 sentencias del libro de los Proverbios, aprovechadas por Tournai para advertir que la religión es la base de toda moralidad y la fuente de la verdadera felicidad. Le siguen 21 citas del Eclesiástico y 20 de los libros de la Sabiduría y Eclesiastés, a razón de 10 citas cada uno. Con las primeras, pretendió enseñar que los que aman la felicidad deben sujetarse a las leyes de la Verdad; con las 20 segundas, aspiraba a discriminar la verdadera sabiduría en el marco de algunas producciones culturales que ya empezaban a desdibujar la imagen de Dios.

En segundo lugar, nuestro franciscano fijó su atención en el libro de los Salmos, a quien citó en 42 ocasiones, en un intento por ensalzar los atributos divinos por los que sentía especial predilección y en los que veía un signo de consuelo para el hombre.

Un tercer y cuarto sillar fueron las 19 citas de los libros históricos y las 19 de los libros proféticos. Con las primeras intentó poner de manifiesto el valor magisterial y didáctico de la Historia; con las segundas, la importancia de la fe como valor insoslayable de la educación.

Cierran la serie 15 citas del Pentateuco llamadas a afianzar las bases de una antropología creada, caída y llamada al reencuentro con el Creador.

El siguiente esquema muestra con más precisión la distribución y frecuencia de todas estas citas:

\begin{tabular}{|c|c|c|c|c|}
\hline Pentateuco & $\begin{array}{c}\text { Libros } \\
\text { históricos }\end{array}$ & $\begin{array}{c}\text { Libros } \\
\text { sapienciales }\end{array}$ & $\begin{array}{c}\text { Libros } \\
\text { proféticos }\end{array}$ & $\begin{array}{l}\text { Libros } \\
\text { varios }\end{array}$ \\
\hline $\begin{array}{l}\text { Génesis........ } 8 \\
\text { Exodo.......... } 4 \\
\text { Números ..... } 1 \\
\text { Deuter.......... } 2\end{array}$ & $\begin{array}{l}\text { I Reyes ......... } 1 \\
\text { II Reyes ....... } 3 \\
\text { III Reyes..... } 3 \\
\text { IV Reyes ....... } 3 \\
\text { Esdras ......... } 1 \\
\text { Tobías.......... } 2 \\
\text { Nehemías.... } 1 \\
\text { Jueces........... } 5\end{array}$ & $\begin{array}{l}\text { Job.............. } 3 \\
\text { Proverbios. } 26 \\
\text { Eclesiastés } 10 \\
\text { Sabiduría .. } 10 \\
\text { Ecles } 10 \\
\text { Can. Cant..... } 2\end{array}$ & $\begin{array}{l}\text { Isaías ........... } 6 \\
\text { Jeremías...... } 5 \\
\text { Ezequiel ...... } 2 \\
\text { Daniel.......... } 3 \\
\text { Oseas ............ } 1 \\
\text { Baruc .......... } 2\end{array}$ & Salmos ...... 42 \\
\hline TOTAL....... 15 & TOTAL ....... 19 & TOTAL ....... 72 & TOTAL....... 19 & TOTAL ....... 42 \\
\hline
\end{tabular}

FUENTES BÍBLICAS VETEROTESTAMENTARIAS (167) 
El Nuevo Testamento, con 57 citas, es la culminación de todo este proceso. Destacan sobremanera las epístolas paulinas con 26 sentencias. Con ellas Tournai refuerza la idea de una antropología pedagógica entendida como restauración de la imagen divina en el hombre, actualizada por la fuerza de la educación moral, la doctrina y la gracia. Ideas que confirman y ratifican las 15 citas de los evangelios y del resto de perícopas en un intento por fortalecer el reencuentro con el Creador como fin primario y último del ser humano.

\begin{tabular}{|c|c|c|c|}
\hline Evangelios & Epístolas paulinas & Otras Epistolas & Libros varios \\
\hline $\begin{array}{l}\text { Mateo ……......... } 13 \\
\text { Marcos ………... } 3 \\
\text { Lucas.................. } 7\end{array}$ & 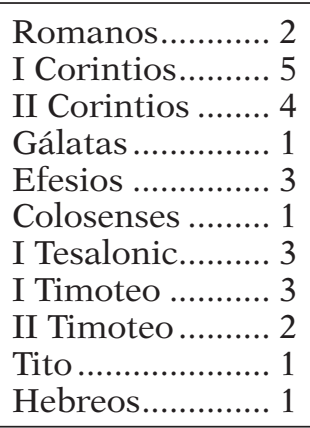 & $\begin{array}{l}\text { Santiago................ } 1 \\
\text { II Pedro ................. } 1\end{array}$ & $\begin{array}{l}\text { Apocalipsis.......... } 1 \\
\text { Hechos ................ } 5\end{array}$ \\
\hline TOTAL................ 23 & TOTAL................ 26 & TOTAL................. 2 & TOTAL .................. 6 \\
\hline
\end{tabular}

FUENTES BÍBLICAS NOVOTESTAMENTARIAS (57)

\subsection{Fuentes patrísticas}

El segundo criterio de verdad para un escolástico eran los doctores o Padres de la Iglesia y Gilbert de Tournai fue un claro exponente. Sus 226 citas: 207 de padres latinos y 19 de padres griegos, suponen el 27,69 por ciento del total y están presentes en la casi totalidad de la obra, bien como eje nuclear de los capítulos, bien como apoyo de otras ideas marco.

En el caso de los padres latinos destaca la omnipresencia de San Agustín y San Jerónimo. El obispo de Hipona no sólo es el autor más citado con 82 referencias directas de 29 de sus obras, sino que éstas, especialmente Confesiones, De doctrina Christiana, De ordine y De trinitate, están auxiliando la totalidad de las seis partes del De modo addiscendi. Dependencia que se hace aún más patente cuando buena parte de los capítulos están elaborados con ideas y palabras literales de San Agustín sin citarlo expresamente. El otro autor omnipresente es San Jerónimo. Sus 43 citas, entresacadas de 20 de sus obras, ilustran directamente argumentos morales de las cuatro primeras partes del De modo addiscendi e indirectamente las dos restantes. 
A estos referentes, que pueden considerarse claves, Tournai añadió otros autores menos influyentes en el conjunto de la obra pero igualmente importantes para una parte de la misma. Tal es el caso, por ejemplo, de las Collationes patrum de Casiano, citadas en 28 ocasiones de la parte quinta por ser ejemplo para el dominio de las pasiones concupiscibles. Otras referencias menos importantes, pero igualmente significativas, fueron los testimonios de San Ambrosio e Isidoro de Sevilla. Ambos aparecen citados en 15 y 8 ocasiones respectivamente para refrendar la importancia de la formación moral. La lista se cierra con referencias mínimas -entre una y cinco- a Gregorio Magno, Ennodio, Beda, Pomerio, Dámaso y Simaco.

De los Padres Griegos sólo se citan 19 referencias y de modo breve. Tournai no dominaba el griego y las traducciones greco-latinas eran escasas. La obra más citada es el De Divinis nominibus del Pseudo-Dionisio que aparece en cinco ocasiones para refrendar su querencia neoplatónica. Le siguen en la misma línea Gregorio Nacianzeno con 4 citas, y las pseudo-clementinas de Clemente romano con tres. El resto apenas tienen relevancia, se refieren a Orígenes, Basilio y Gregorio Niseno.

\begin{tabular}{|c|c|}
\hline \multicolumn{2}{|c|}{ Padres Latinos (207) } \\
\hline Agustín........................................... 82 & Hilario de Poitiers ....................... \\
\hline Ambrosio ...................................... & Isidoro de Sevilla........................ 8 \\
\hline 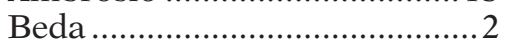 & Jerónimo...................................... 43 \\
\hline 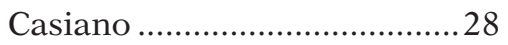 & 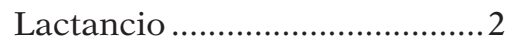 \\
\hline Casiodoro............................... & Nemesio de Emesa....................... 3 \\
\hline 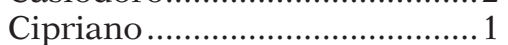 & Pomerio Julián ……………....... 5 \\
\hline Dámaso (Papa) …….................... 4 & Próspero de Aquitania ................. 1 \\
\hline 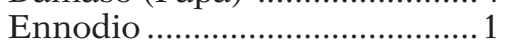 & 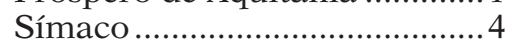 \\
\hline Gregorio Magno ......................... 4 & \\
\hline
\end{tabular}

\begin{tabular}{|c|c|}
\hline \multicolumn{2}{|c|}{ Padres Griegos (19) } \\
\hline (2). & Gregorio Nazianceno........ \\
\hline mo …….................... 1 & Gregorio Niseno ........................ 3 \\
\hline Clemente de Roma (Pseudo) ...3 & 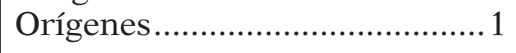 \\
\hline Pseudo Dionisio . & \\
\hline
\end{tabular}

\begin{tabular}{|l|}
\hline \multicolumn{2}{|c|}{ Autores Cristiano-Latinos (8) } \\
\hline Constantino ………….................. 8 \\
\hline
\end{tabular}

\subsection{Autores antiguos}

El tercer bloque de sentencias lo conforman autores antiguos. Su peso es extraordinariamente significativo a la hora de fundamentar la cien- 
cia secular y la praxis moral tournacense. En concreto fueron 37 autores que prestaron a nuestro franciscano 206 citas, el 25,24\% del total. Están presentes en la práctica totalidad de capítulos, bien combinándose con fuentes bíblicas y patrísticas, bien constituyéndose en argumento principal de autoridad. Especialmente relevantes resultan las 63 referencias de Lucio Anneo Séneca, entresacadas en 52 casos de las Cartas a Lucilio, en 10 del De clementia y en una del De beneficiis. Obras que inspiraron cinco de las seis partes — falta la quinta- del De modo addiscendi, poniendo de manifiesto el notable influjo del sabio cordobés en la obra tournacense. Situación parecida ocurre con las 39 citas de Cicerón, repartidas en 12 obras que están presentes en las cuatro primeras partes, donde destacan: la anima Rethorica ad Herenium, De inventione y De oratote. A estas referencias cabe unir las 10 citas de las Instituciones oratorias de Quintiliano, las diez de Horacio y las 14 de un Ovidio aparentemente cristianizado, lo que confirma el notable peso de la humanitas romana en la fundamentación de la moral escolástica. En lo que respecta a los autores griegos cabe decir que apenas tuvieron significación. Las 12 citas del llamado "Nuevo Aristóteles» como las 2 de Platón fueron escuetas, con un afán complementario y de novedad retórica.

\begin{tabular}{|c|c|c|}
\hline \multicolumn{3}{|c|}{ Autores Antiguos: [206] } \\
\hline Apuleyo ………............. 1 & Macrobio ................... 3 & Salustio Crispo ........... 1 \\
\hline Aristóteles ...................12 & Marcial..................... 1 & Séneca, L. Anneo.....63 \\
\hline Balbo Callici ................ 1 & Maximiano ….............. 1 & Séneca, M. Anneo....... 1 \\
\hline Caldicio ……............. 1 & Ovidio ....................... 14 & Sidonio Apolinar ........1 \\
\hline Catón (Díst) ................... 3 & Paladio ............................. 1 & Sirio Publilio .............. 1 \\
\hline Cicerón........................ 39 & Platón.......................... 2 & 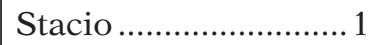 \\
\hline Claudiano ………............. 3 & Plauto (Pseudo) .......... 1 & Terencio ........................ \\
\hline Galeno........................ 1 & Plauto Maccio.............. 1 & Valerio Máximo ........... 1 \\
\hline Hermes $\mathrm{T}^{\text {rismegisto }} . . . . . . . . .11$ & Plinio el Joven ............. 1 & Varrón (Pseudo) ......... 8 \\
\hline Horacio .................... 12 & Plinio el Viejo .............. 3 & 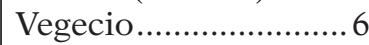 \\
\hline Julio César ..................... 1 & Ptolomeo..................... 1 & Virgilio …….............. 4 \\
\hline Lucano ....................... 1 & Quintiliano Pseudo ... 1 & \\
\hline Lucrecio Tito ............... 1 & Quintiliano …............ 10 & \\
\hline
\end{tabular}

\subsection{Autores medievales}

Por lo que se respecta a las referencias medievales cabe decir que presentan dos matices importantes: las citas contienen menos errores por tomarse de fuentes directas, y son más compactas al concentrar los argumentos de autoridad en tres obras pedagógicas que marcaron la educación escolástica: el Didascalicon de studio legendi de Hugo de San Víctor, el De disciplina scholarium del Pseudo-Boecio y el De eruditione filiorum nobilium de Vicente de Beauvais. Las dos primeras, con 20 y 19 referencias respectivamente, y la tercera, con la apariencia de sólo dos citas directas, constituyen 
referentes clave de la pedagogía de Gilbert de Tournai y de buena parte de la educación escolástica.

El Didascalicon vitorino es sin duda el sillar por excelencia de la pedagogía escolástica. Tournai lo utiliza en la segunda y cuarta parte del De modo addiscendi para justificar el sentido del estudio, la clasificación de las ciencias y el modo en que hay que estudiar, pensar y meditar. El De disciplina scholarium del Pseudo-Boecio está de forma omnipresente en las cuatro primeras partes auxiliando la naturaleza y el modo de actuar del maestro y del discípulo. Mención aparte merece el De eruditione filiorum nobilium de Vicente de Beauvais que, aunque es citado en dos ocasiones, está más presente de lo que en principio aparenta. Tournai conocía muy bien la obra de Vicente de Beauvais y, sin citarlo expresamente, copió buena parte de su estructura y las fuentes de los capítulos referidos al estudio, al maestro y al discípulo ideal.

Otros autores completan este trío con participaciones selectivas en determinados capítulos de la obra. Tal es el caso de los Sermones de Bernardo de Claraval, el De spiritu et anima de Alcherus, la Scala claustralium de Guido Carthusiensis y el Beniamin maior de Ricardo de San Víctor. Las dos primeras están presentes en la IV parte del De modo addiscendi ilustrando la afirmación del espíritu y la necesidad de autocontrol, la tercera prácticamente resume la parte sexta ilustrando la manera correcta de orar, mientras que el Beniamin maior victorino ilustra varios capítulos de la IV parte relativos a los progresos en el perfeccionamiento interior. El resto de autores son muy variados, lo que pone al descubierto que Tournai conocía muy bien la literatura de su tiempo, pero son citas cortas y de escasa significación. Igual podría decirse de las trece referencias que hace a los autores árabes, citas que son un apoyo a otros capítulos sobre el currículum y la división de los saberes.

\begin{tabular}{|c|c|}
\hline \multicolumn{2}{|c|}{ Autores árabes (13) } \\
\hline $\begin{array}{l}\text { Alfarabi } \\
\text { Algazel..................... } 2\end{array}$ & $\begin{array}{l}\text { Averroes ....................... } 6 \\
\text { Avicena }\end{array}$ \\
\hline \multicolumn{2}{|c|}{ Literatura pedagógica medieval(130) } \\
\hline Alcherus de Claraval ....... 9 & Cartusiano Guido........... 17 \\
\hline Anselmo de Canterbury ... 2 & Hugo de San Víctor........ 27 \\
\hline Beauvais Vicente de ........ 2 & Ricardo de San Víctor... 29 \\
\hline Bernardo de Claraval .... 10 & Salisbury Juan de ............. 3 \\
\hline Boecio Pseudo …………... 19 & Tournai Gilbert de............ 2 \\
\hline Comestor Pedro.................. 2 & Walafrido Estrabón........... 2 \\
\hline Capella ............................ 6 & \\
\hline
\end{tabular}




\begin{tabular}{|l|l|}
\hline \multicolumn{3}{|c|}{ Miscelánea medieval (9) } \\
\hline Aelredo de Rievaulx ........ 1 & Hugo de Folieto............... 1 \\
Cantor Pedro ................ 1 & Graciano ......................... 1 \\
Cartaginense Fonteo ...... 1 & Lombardo Pedro ............ 1 \\
Castellone Guâlterio de... 1 & Plutarco (Pseudo)........... 1 \\
Hildeberto de Lavardin... 1 & \\
\hline
\end{tabular}

Tras este panorama de fuentes diversas, la pregunta que cabe formularse es si Tournai conoció directamente todas las obras que cita o muchos de los textos los copió de colecciones o florilegios de su tiempo. Quizá la pregunta resulte ociosa, ya que la respuesta parece obvia: muchos textos están sacados de obras directas, especialmente cuando se trata de textos largos y continuos; en cambio los cortos y ocasionales, puramente de apoyo o retóricos, son más propios de colecciones de su tiempo. Aun así debe decirse que Tournai es el autor de su obra, no es un mero recopilador de sentencias, sino el constructor de un edificio bastante original llamado De modo addiscendi.

\section{SIGNIFICADO Y PROYECCIÓN}

¿Qué representa el De modo addiscendi en la pedagogía escolástica? ¿Es una coloquíntida [flor de segundo orden] — como la llama el propio Tournai-que sigue la estela recurrente y repetitiva de muchas de las obras de esa época? Rotundamente no. Si la unimos al Rudimentum doctrinae podemos decir que estamos ante uno de los tratados pedagógicos más importantes de la pedagogía escolástica. Un tratado que definió buena parte de la pedagogía franciscana, concretada sobremanera en el cultivo del hombre interior y en la pedagogía contemplativa.

Es cierto que con anterioridad el Didascalicon de studio legendi (c.1130) de Hugo de San Víctor, el De disciplina scholarium (c.1190) del PseudoBoecio y sobre todo el De eruditione filiorum nobilium (1246) de Vicente de Beauvais habían intentado sistematizar y ahondar en la estructura noética de la educación. Pero ninguno alcanzó la hondura, extensión y sistematicidad del De modo addiscendi. Se trataba de obras que, con un discurso apoyado en sentencias del pasado, buscaban alcanzar la sabiduría mediante la excelencia de la educación moral, intelectual y religiosa. El De modo addiscendi fue otra cosa. Su discurso, apoyado en el uso de la quaestio y no en la lectio, compartió muchas de las ideas anteriores sobre educación moral, intelectual y religiosa, pero para un franciscano de su tiempo la sabiduría era transitar a la santidad por la virtualidad de la humildad, la meditación y la contemplación. 
Esto no significó que los manuscritos del Tournacense fuesen tan abundantes como los de otros pedagogos de su tiempo. Es más, sus manuscritos pedagógicos son más bien escasos. Las razones, aunque variadas, quizá puedan circunscribirse a dos hechos significativos: en primer lugar, Tournai como pedagogo tuvo una preocupación más teórica que didáctica en un momento donde conocer cómo llegar a la verdad interesaba tanto como la verdad misma; en segundo lugar, su cultivo del hombre interior contrastó en buena parte con el devenir de una cultura que demandaba mayores dosis de secularidad. Aun así la historiografía se ha hecho eco de seis manuscritos del De modo addiscendi (Troyer, 1974, 19-20).

1. Florencia: Biblioteca Laurenciana, S. Croce Plut. 36, dext. 6, ff, 238v-309.

2. París: Biblioteca Nacional, cod. lat. 15.451, f. 227r-268r.

3. Edimburgo: Biblioteca universitaria, cod 111. (D.B. I, 12), f. 144v. 192r.

4. Cracovia: Biblioteca Jagiellonska, cod. 690 AA. VIII, 25, ff. 316-423.

5. Cracovia: Biblioteca Jagell., cod. 574, AA. VIII, 34, f. 1-137

6. Bibliotheque de Bruges, ms. Cote 441, Stadsbibl. 289 ff. 1-276v

Esta falta de proyección se nota igualmente en los incunables; si los buscamos, no encontramos referencia explícita a nuestra obra. Hubo que esperar a 1953 para que Enrico Bonifacio hiciese una edición crítica latina - a la que le falta una notable acribia filológica y pedagógica- que no ha encontrado traducción o estudios posteriores significativos. Sí hubo trabajos previos que ahondaron en la obra pedagógica de Tournai, pero sin apenas profundizar en su sentido y significación. Uno de los primeros fue el de A. Poorter, quien en 1922 publicó en Un traité de pédagogie médiévale, le De modo addiscendi de Gilbert of Tournai, Revue néo-scolastique de philosophie, Louvain, pp. 195-228. El artículo se redujo a pequeñas referencias biográficas, textuales y estructurales de la obra. Lo mismo puede decirse del trabajo de P. Glorieux, quien en 1933 publicó en París Répertoire des Maîtress en Théologie de Paris au XIII siècle.

La historiografía de la segunda mitad del siglo XX ha venido marcada por la publicación de Enrico Bonifacio, que alentó un mayor interés por la obra pedagógica de nuestro franciscano. Uno de los ejemplos más interesantes es el trabajo de Servus Gieben «Four Chapters on Philosophical Errors from the Rudimentum Doctrine of Gilbert of Tournai», publicado en Vivarium 1 (1963), pp. 141-164. El artículo ahonda en el agustinismo de nuestro franciscano y más en concreto en su doctrina de la iluminación. Tema que Gieben amplió, en colaboración con Camile Bérubé, en 1973, en un trabajo titulado: "Guibert de Tournai et Robert Grosseteste. Sources inconnues de la doctrine de l»illumination, suivi de l»édition critique de trois chapitres du Rudimentum Doctrinae de Guilbert de Tournai», en: S. Bonaventura, 1274-1974 (Grottaferrata, 1973), II, 627-654. Estos trabajos, que ahondan 
en índices y partes de Rudimentum, se han visto confirmados en 1988 por las investigaciones de Pietro Maranesi quien, apoyado por los trabajos de Servus Gieben, comenta sus partes en: «Il «Rudimentum Doctrinae» di Gilberto di Tournai con l«edizione del suo «registrum» o tavola della materia», en: Bonaventuriana. Miscellanea in onore di Jacques Guy Bougerol, OFM, 2 Vols, ed. C. Blanco (Rome, 1988), II, 621-680.

La pedagogía política se ha hecho igualmente eco de nuestro personaje. Uno de los trabajos más importantes es el de A. Poorter, quien en 1914 publicó un trabajo, ya clásico, para el conocimiento de la educación política de nuestro franciscano: Guibert de Tournai, O. F. M., Le traité "Eruditio regum et principum» (étude et texte inédit). Lovaina: Institut Supérieur de Philosophie de l»Université, col. Les philosophes belges. Textes et etudes, tomo IX. 


\section{REFERENCIAS BIBLIOGRÁFICAS}

Gieben, S. et Bérubé, C. (1973). Guibert de Tournai et Robert Grosseteste. Sources inconnues de la doctrine de l»illumination, suivi de l»édition critique de trois chapitres du Rudimentum Doctrinae de Guilbert de Tournai, en S. Bonaventura, 1274-1974, Grottaferrata, II, 627-654.

Gieben, S. (1963). Four Chapters on Philosophical Errors from the Rudimentum Doctrine of Gilbert of Tournai, Vivarium, 1, 141-164.

Glorieux, P. (1933). Répertoire des Mâิtress en Théologie de Paris au XIII ${ }^{\mathrm{e}}$ siècle. París: J. Vrin, vol. II.

Maranesi, P. (1988). Il «Rudimentum Doctrinae» di Gilberto di Tournai con l«edizione del suo «registrum» o «tavola della materia», en Blanco, C. (ed.) Bonaventuriana. Miscellanea in onore di Jacques Guy Bougerol, OFM, 2 Vols, Rome, II, 621-680.

Poorter, A. (1922). Un traité de pédagogie médiévale, le De modo addiscendi de
Gilbert of Tournai, Revue néo-scolastique de philosophie, XXIV, Louvain, 195-228.

Poorter, A. (1953). Le Traité «Eruditio Regium et Principum» de Guibert de Tournai, O, F. M., Lovaina.

Tournai Gilbert de (1953). De modo addiscendi. Introduzione e testo inedito a cura di E. Bonifacio. Torino: Societá Editrice Internazionale.

Troeyer de B. (O.F.M.) (1974). Bio-bibliographia franciscana neerlandica ante saeculum XVI. Pars Biographica. Nieuwkoop: B. de Graaf.

Vergara, J. (2007). El De modo dicendi et meditandi de Hugo de San Víctor. Una lectio sobre la pedagogía del siglo XII, Revista Española de Pedagogía, 238, 519-545.

Vergara, J. (2003). La didáctica bajomedieval: una apuesta por la pedagogía activa, Revista Española de Pedagogía, 226, 511-526. 


\section{PALABRAS CLAVE}

Gilbert de Tournai, De modo addiscendi, Edad Media, Educación, sabiduría, contemplación.

\section{KEY WORDS}

Gilbert of Tournai, De modo addiscendi, Middle Ages, Education, Wisdom, Contemplation.

\section{PERFIL ACADÉMICO Y PROFESIONAL DEL AUTOR}

Javier Vergara Ciordia, Profesor Titular de Historia de la Educación en la Universidad Nacional de educación a Distancia. Es director del Grupo de Estudios Medievales y Renacentistas (GEMYR) y director de la Collectio Scriptorum Mediaevalium et Renascentium, colección editada por la editorial B.A.C., dedicada a publicar obras bilingües medievales y renacentistas que han marcado la cultura europea.

Dirección del autor: Facultad de Educación

UNED

C/ Juan del Rosal, 14

28040 Madrid

E-mail: fvergara@edu.uned.es

Fecha Recepción del Artículo: 27. Enero. 2012

Fecha Aceptación del Artículo: 06. Junio. 2012

Fecha Revisión para publicación 09. Noviembre. 2012 